\title{
A Modeling Strategy for Predicting the Properties of Paraffin Wax Actuators
}

\author{
Arne Mann $\mathbb{D}$, Christoph Maria Bürgel and Peter Groche * \\ Institute for Production Engineering and Forming Machines, Technische Universität Darmstadt, 64287 \\ Darmstadt, Germany; mann@ptu.tu-darmstadt.de (A.M.) \\ * Correspondence: groche@ptu.tu-darmstadt.de; Tel.: +49-6151-16-23143
}

Received: 26 October 2018; Accepted: 27 November 2018; Published: 28 November 2018

\begin{abstract}
In production processes, many adjustment tasks have to be carried out manually. In order to automate these activities, there is a need for cost and space efficient actuators that can provide comparatively high forces. This paper presents a novel actuator concept based on the phase change material paraffin wax. Furthermore, a numerical modelling strategy is introduced enabling the prediction of actuator properties. The model considers paraffin wax as a deformable body. The temperature-dependent volume expansion data of the paraffin wax is obtained experimentally to allow for a realistic description of the thermal-mechanical properties. The simulation is verified, using experimental data from actuators with varying paraffin wax volumes. With a maximum deviation of $6 \%$, the simulations show a good agreement with the experiments.
\end{abstract}

Keywords: paraffin wax; actuator; phase change material; simulation; FEM

\section{Introduction}

More and more production processes are equipped with sensors to generate a better process understanding using the generated data to correlate cause and effect. The next level in process automatization is to control the product properties by reacting to the measured values with a suitable actuating variable [1]. To reach this degree of automatization, there is the need for suitable actuators to control the designated actuating variables. The actuator principles for the main drives of forming machines are set, whereas alternative actuator concepts are required for auxiliary drives. Thermal expansion is a promising actuator principle, especially when paraffin wax is employed.

Paraffin wax is used in numerous applications as microactuators [2-6], valves [7-9], and pumps $[10,11]$. Paraffin wax is a phase change material which generates a significant volume increase while changing from solid to liquid phase $\left(\mathrm{C}_{24} \mathrm{H}_{50}\right.$ up to $22.9 \%$ at $80{ }^{\circ} \mathrm{C}$ compared to $30{ }^{\circ} \mathrm{C}$ [12]). The volume increase is utilized by a housing to achieve a directed force or a displacement, or both. In order to design sufficient actuator housings, paraffin wax is modeled in FEM simulations with the aim to predict the targeted properties of the actuator. There are various challenges to address when the behavior of paraffin wax is modeled in a FEM simulation. Below the melting temperature, paraffin wax acts as a solid body with a pseudoplastic material behavior [13]. Above the melting temperature, paraffin wax behaves like a compressible liquid. In the melting area, paraffin wax shows a shear thinning behavior.

Ogden et al. give an overview over the modeling strategies for paraffin wax and summarize that a modeling as a fluid has the advantages of conforming to shape changes and modeling a more veridical thermal conductivity relating to natural convection [14]. Hence et al. [15] and Costa et al. [16] perform basic numerical investigations on latent heat thermal energy storage systems by improving the response times by fins. Further investigations on latent heat thermal energy storage systems by Brousseau and Lacroix focus on the thermal behavior of phase change materials [17]. Kratz et al. 
include paraffin wax as a heat sink in their thermal investigation on silicon-based heat dissipation stages [18]. Lee et al. performed a thermal analysis locating the melting front of the paraffin wax [19] and a pressure analysis of an electro thermohydraulic microactuator [20]. The focus of this investigation lies on the thermal behavior of paraffin wax. It reaches a good accordance of the predicted and actual melting fronts of the used paraffin wax. Gowreesunker et al. enhanced a phase change simulation by implementing user defined temperature-dependent specific heats, which are varied for heating and for cooling [21]. The modeling utilized a flow simulation to evaluate phase change materials as an energy storage material in buildings. Kong et al. performed a numerical investigation on the volumetric change rate for a cylindrical container during the solid to liquid phase change process for energy conversion systems [22]. Malik et al. present a numerical simulation in which the paraffin wax of the micro actuator is modeled as a liquid in the solid and liquid phase with varying density and viscosity [23].

Bodén et al. conduct a thermo-mechanical modeling of a paraffin wax powered miniaturized pump [24]. The volume increase is implemented by a temperature-dependent density. For modeling the heat conduction, the specific heat is temperature-dependent, too. The thermal conductivity is set to $0.24 \mathrm{~W} /(\mathrm{m} \mathrm{K})$ below $48{ }^{\circ} \mathrm{C}$ and to $5 \mathrm{~W} /(\mathrm{m} \mathrm{K})$ equal and above $48{ }^{\circ} \mathrm{C}$ to fulfill the liquid paraffin behavior. The modeled micropump generates pressures up to $5.6 \mathrm{~N} / \mathrm{mm}^{2}$, whereby the compressibility of the paraffin wax is neglected. To achieve plausible data, the convection was adjusted in a static analysis to reach a stroke volume close to the lowest experimentally measured frequency. Furthermore, the thermal transport into and out of the system is adjusted to reach a steady-state stroke volume of the paraffin wax. For a driving frequency below $0.19 \mathrm{~Hz}$, the model shows a good agreement with the experimentally measured flow rate. Above this frequency, the model overestimates the given flow rate [24].

Mostly, the approaches differ in modeling paraffin wax as a solid or as a liquid, depending on the modeling objectives. Odgen et al. summarize that modeling paraffin wax as a thermally expanding solid is a simpler approach, because only solid mechanics and thermal properties need to be addressed [14]. The major focus in present investigations is the thermal behavior of paraffin wax. There seems to be a lack of a thorough thermo-mechanical modeling with all thermal and mechanical properties addressed. The modeling strategy depends on the simulation objective, whereas predicting the actuator forces using paraffin wax modeled as a solid is not yet an objective. In the following, a thermo-mechanical modeling of the paraffin wax as a deformable body is performed, with the aim of predicting the actuator properties with the actuator forces in focus. Furthermore, a possibility is provided to obtain the fundamental volume expansion data for the issued paraffin wax.

After presenting the new actuator design for high acting forces and the modeling strategy, the used piston-cylinder test set-up is presented, which is used to obtain the material data and to verify the paraffin wax model in the simulation. Then, the actuator is implemented in the simulation using the established paraffin wax model. Finally, experimental tests verify the simulations.

\section{Paraffin Wax Actuator Design and Modeling Strategy}

Figure 1 introduces the closed paraffin wax actuator design. The shown housing completely encloses the paraffin wax. The design includes no moving parts or relative movements. The actuator acts as a membrane design, so that a deflection of the top and bottom of the actuator and a reversible extension of the actuator wall generates displacements and forces. Sheet metal housings allow for high internal pressures and actuating forces. Furthermore, a cylinder can be integrated in the actuator center (Figure 1b). The cylinder provides a known compressive strength in axial direction and additionally provides the possibility to vary the paraffin volume by changing the cylinder diameter $d_{\mathrm{c}}$ compared to an actuator design without cylinder (Figure 1a).

The actuator consists of two deep drawn cups which fit into each other. Both cups have specific heights, whereby a weld area is created. The welding process necessary generates heat, which distributes within the actuator during the joining process. The induced heat leads to a volume increase 
of the paraffin wax. To prevent paraffin wax from leaking out of the cavity or damaging the weld seam, a cutting sealing is integrated into the housing design. The inner cup has an additional chamfer at the cup's wall tip. As seen, the chamfer is positioned at the outer cups internal bottom, on which a brass sheet (thickness $50 \mu \mathrm{m}$ ) is placed. Due to an axial force which can be applied during the welding process, the chamfer at the inner cup's edge cuts into the brass sheet and establishes a sealing.

(a)

(b)

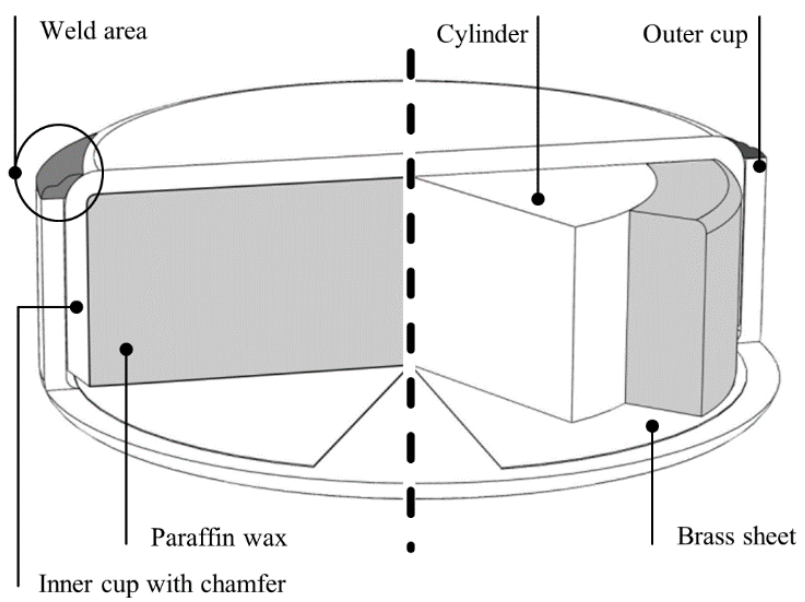

Figure 1. Design of the phase change actuator in a sectional view. Without integrated cylinder (a) and with cylinder $(\mathbf{b})$.

On the one hand, the rigid actuator housing enables high forces. On the other hand, it limits the possible displacements. For a target-oriented design, the use of a finite element modeling of the actuator behavior seems promising. As the presented actuator design leaves the expectation for small displacements, a thermo-mechanical modeling as a deformable body seems applicable, whereas the implementation takes place in the software environment Simulia Abaqus (version 6.14-1, Dassault Systèmes®, Vélizy-Villacoublay, France).

The following material properties are required for a sufficient modeling of the paraffin wax: density, Young's modulus, Poisson's ratio, elastic limit, thermal expansion coefficient, specific heat, latent heat, and thermal conductivity. The temperature-dependent thermal expansion coefficient models the volume expansion, which is generated by the transition from the solid to the liquid phase. In combination with the correct Young's modulus the compressibility of the paraffin wax is implemented. The elastic limit allows to distribute stress peaks for an even stress distribution. The thermal properties model the heat distribution within the paraffin wax. The paraffin wax with a melting range of $58-62{ }^{\circ} \mathrm{C}$ is issued (SIGMA-ALDRICH paraffin wax mp $58-62{ }^{\circ} \mathrm{C}$ ). Literature data can be used for most paraffin wax properties (Table 1). The coefficient of thermal expansion and the Young's modulus are of special importance for an accurate force prediction. Therefore, they are recorded in an experimental set-up which is described as follows.

Table 1. Material properties.

\begin{tabular}{cccc}
\hline & Steel Grad 1.2379 & Paraffin Wax & Sheet Metal DP600 \\
\hline Density in $10^{-9} \mathrm{t} / \mathrm{mm}^{3}$ & 7.70 & $0.893[25]$ & 7.90 \\
Young's modulus in N/mm & 210,000 & Stated blow & 209,000 \\
Poisson's ratio & 0.3 & $0.37[26]$ & 0.3 \\
Elastic limit in $\mathrm{N} / \mathrm{mm}^{2}$ & - & $1.80\left(25^{\circ} \mathrm{C}\right), 0.36\left(30^{\circ} \mathrm{C}\right)[27]$ & 340.00 \\
Expansion Coefficient in $10^{-5} \mathrm{~mm} /{ }^{\circ} \mathrm{C}$ & 1.2 & Recorded blow & 1.2 \\
Conductivity in $\mathrm{W} / \mathrm{mK}$ & 16.70 & $0.21\left(25^{\circ} \mathrm{C}\right), 4.2\left(58^{\circ} \mathrm{C}\right)[10,25]$ & 48.00 \\
Specific heat in $10^{7} \mathrm{~mJ} / \mathrm{tK}$ & 46 & $\mathrm{~F}(\mathrm{~T}) 210-249\left(0^{\circ} \mathrm{C}-62^{\circ} \mathrm{C}\right)[25]$ & 50 \\
Latent heat in $10^{9} \mathrm{~mJ} / \mathrm{t}$ & - & 253.520 Solidus $58^{\circ} \mathrm{C}$, & - \\
\hline
\end{tabular}




\section{Paraffin Wax Characterization and Verification of Modeling Using a Piston-Cylinder Test Set-Up}

Figure 2 shows the piston-cylinder test set-up for the paraffin wax characterization and the verification of modeling. There are eight heating cartridges positioned around the circumference of the cylinder wall for an even temperature distribution. One heating cartridge is placed in the piston. Furthermore, there are three pressure sensors located in the cylinder (1-3 in Figure 2 top view). Four thermocouples are positioned at the bottom of the cylinder. One thermocouple is placed in the middle (a) and three thermocouples are placed at the radius $r_{1}(b, c$, and $d)$. At the positions of the pressure sensors, thermocouples can substitute the sensors to obtain the paraffin temperature at the cylinder wall $(\mathrm{e}, \mathrm{f})$. Together, the cylinder and the piston generate the paraffin wax chamber with the height $h_{\mathrm{c}}$ and radius $r_{\mathrm{c}}$. The piston-cylinder set-up is placed in a compression test machine (Zwick Roell 100). The compression test machine records the displacement of the cylinder height $\Delta h_{\mathrm{p}}$ using a video extensometer and the axial force $F_{\mathrm{a}}$. The heating cartridges are controlled and their temperature data $\left(\theta_{\mathrm{a}}, \theta_{\mathrm{b}}, \theta_{\mathrm{c}}, \theta_{\mathrm{d}}, \theta_{\mathrm{e}}\right.$, and $\left.\theta_{\mathrm{f}}\right)$ is recorded as well as the pressure data $\left(p_{1}, p_{2}\right.$ and $\left.p_{3}\right)$.

Using the piston-cylinder test set-up, two different tests are performed to record the free expansion of the paraffin wax and to record the compressibility. The free expansion is used to calculate the coefficient of thermal expansion $\alpha$. The compressibility is used to calculate the Young's modulus $E$. Prior to both tests, the paraffin wax is bled to remove air form the chamber, the paraffin height $h_{\mathrm{c}}$ is measured and weighed.

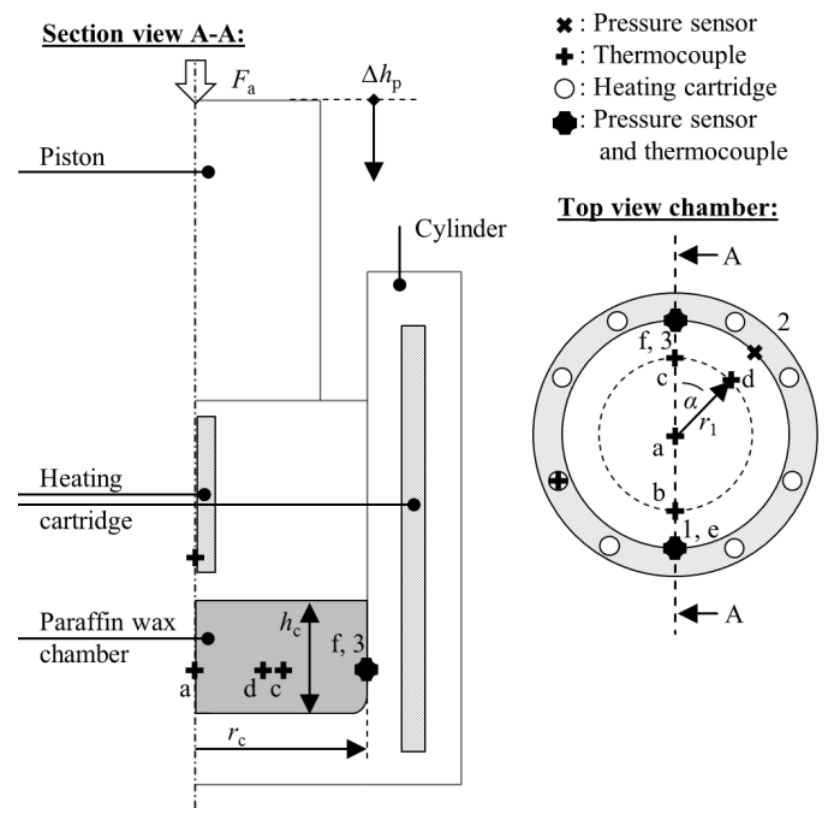

Figure 2. Piston-cylinder test set-up.

Table 2 shows the temperature distribution which occurs in the paraffin chamber when the paraffin wax data is obtained in one test. Average, minimal, maximum temperature and the standard deviation are shown to demonstrate the data consistency.

Table 2. Temperature distribution in piston-cylinder set-up.

\begin{tabular}{cccc}
\hline Average Temperature in ${ }^{\circ} \mathbf{C}$ & Minimal Temperature in ${ }^{\circ} \mathbf{C}$ & Maximum Temperature in ${ }^{\circ} \mathbf{C}$ & Standard Deviation in ${ }^{\circ} \mathbf{C}$ \\
\hline 29.4 & 29.4 & 29.5 & 0.04 \\
44.5 & 43.1 & 46.2 & 1.25 \\
60.4 & 59.6 & 61.7 & 0.94 \\
75.1 & 73.8 & 77.2 & 1.51 \\
90.0 & 88.7 & 92.2 & 1.52 \\
\hline
\end{tabular}


To achieve the coefficient of thermal expansion $\alpha$, the following equation is used with linear thermal strain $\varepsilon_{1}$ and the temperature change $\Delta \theta$.

$$
\varepsilon_{1}=\alpha \Delta \theta \leftrightarrow \alpha=\frac{\varepsilon_{1}}{\Delta \theta}
$$

The linear thermal strain $\varepsilon_{1}$ can be calculated using the free expansion. For recording the free expansion, the piston is loaded with an axial force $F_{\mathrm{a}}=150 \mathrm{~N}$ to secure an enduring paraffin wax contact and the resulting piston height $h_{\mathrm{p}}$ is recorded. Using the temperature control, the target temperature $\theta_{\mathrm{t}}$ is set and held until a minimal temperature deviation is obtained (Table 2). The given piston-cylinder test set-up records the change in piston height $\Delta h_{\mathrm{p}}$ occurring due to a given temperature change $\Delta \theta$. As reference temperature, the given room temperature is recorded $\left(\theta_{\mathrm{RT}}=27^{\circ} \mathrm{C}\right)$. To receive the volume expansion $\varepsilon_{\mathrm{v}}$ the following equation is used:

$$
\varepsilon_{V}=\frac{\Delta V}{V_{0}}=\frac{\pi r^{2} \Delta h_{\mathrm{p}}}{\pi r^{2} h_{0}}=\frac{\Delta h_{\mathrm{p}}}{h_{0}}
$$

The resulting volume expansion $\varepsilon_{\mathrm{V}}$ out of three measurements, depending on the temperature $\theta$ is shown in Figure 3. For temperatures higher than $75^{\circ} \mathrm{C}$, the volume expansion is extrapolated.

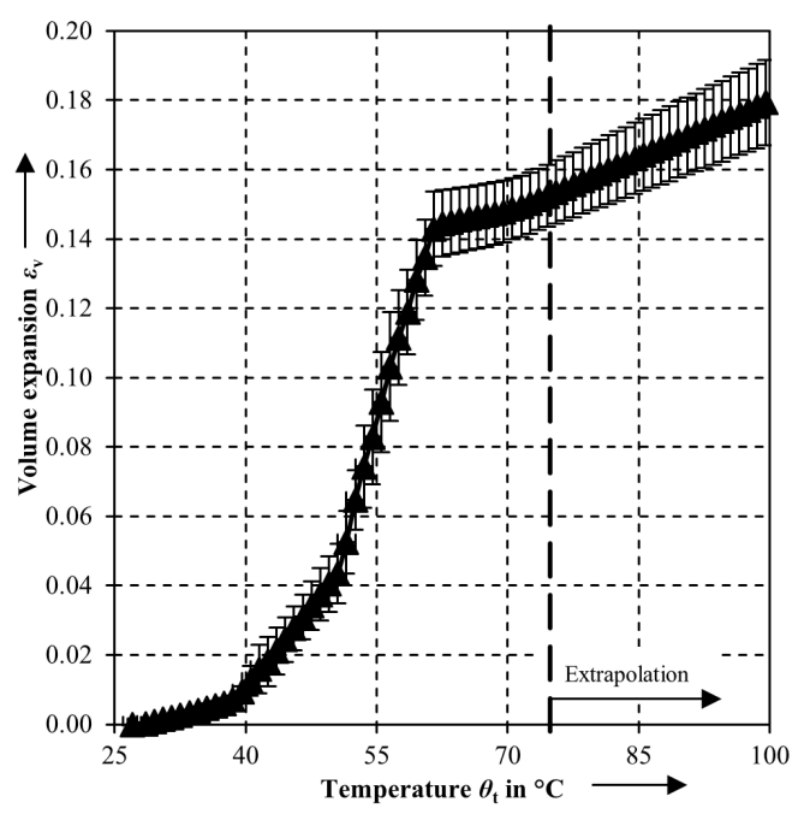

Figure 3. Recorded volume expansion data.

The following equations are used to reduce the volume expansion $\varepsilon_{\mathrm{v}}$ to a linear thermal strain $\varepsilon_{1}$.

$$
\begin{gathered}
V_{1}=V_{0}(1+\alpha \Delta T)^{3}=V_{0}\left(1+\varepsilon_{1}\right)^{3} \\
V_{1}-V_{0}=\Delta V=V_{0}\left(1+\varepsilon_{1}\right)^{3}-V_{0} \\
\varepsilon_{\mathrm{V}}=\left(1+\varepsilon_{1}\right)^{3}-1 \\
\varepsilon_{1}=\left(\varepsilon_{\mathrm{V}}+1\right)^{\frac{1}{3}}-1
\end{gathered}
$$

Compression tests are performed for the determination of the temperature-dependent Young's modulus at various target temperatures $\theta_{\mathrm{t}}$. In this way, the bulk modulus $K$ is experimentally recorded and the Young's modulus is calculated using the following equation:

$$
E=3(1-2 v) K
$$


For defining the bulk modulus $K$, the piston-cylinder test set-up is heated up to the target temperature $\theta_{\mathrm{t}}$. After reaching the target temperature $\theta_{\mathrm{t}}$, an axial force $F_{\mathrm{a}, \max }=75 \mathrm{kN}$ is applied on the piston and the resulting displacement of the cylinder height $\Delta h_{\mathrm{p}}$ is recorded. Figure 4 shows exemplarily the experimental results for the compression at the target temperature $\theta_{\mathrm{t}}=65^{\circ} \mathrm{C}$.

The compression of the paraffin wax is repeated ten times to calculate the bulk modulus. The first compression is used to release the remaining air from the paraffin wax chamber and is excluded from the evaluation. The following nine compression graphs show a good correlation. The nonlinear area until $\Delta h_{\mathrm{p}}=0.2 \mathrm{~mm}$ appears due to settlement effects in the piston seal. For the evaluation of the bulk modulus, only the linear area is used performing a linear regression. The bulk modulus $K$ is defined as followed with $\Delta \mathrm{V}$ as volume difference, $V_{0}$ as initial volume, $\Delta p$ pressure difference, $h_{0, \theta}$ as initial absolute piston height at target temperature $\theta_{\mathrm{t}}$, and $A$ as piston face.

$$
\Delta V=-\frac{V_{0} \Delta p}{K} \rightarrow K=-\frac{V_{0} \Delta p}{\Delta V}
$$

Using

$$
\frac{V_{0}}{\Delta V}=\frac{\pi r_{\mathrm{c}}^{2} h_{0, \theta}}{\pi r_{\mathrm{c}}^{2} \Delta h}=\frac{h_{0, \theta}}{\Delta h_{\mathrm{p}}}
$$

and

$$
\begin{gathered}
\Delta p=\frac{\Delta F_{\mathrm{a}}}{A} \\
K=-\frac{h_{0, \theta}}{A} \frac{\Delta F_{\mathrm{a}}}{\Delta h_{\mathrm{p}}}
\end{gathered}
$$

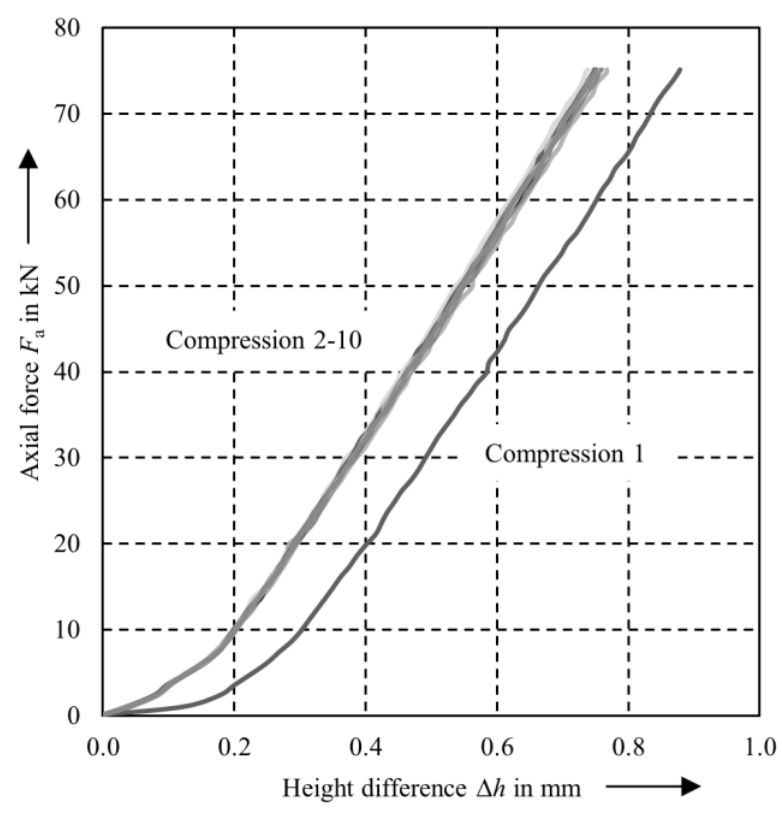

Figure 4. Experimental data for the compression module $\theta_{\mathrm{t}}=65^{\circ} \mathrm{C}$.

Table 3 shows the experimental results. The table summarizes the gradient of change of force and change of paraffin height, the deviation of the gradient, the change of the initial absolute piston height at the temperature $\theta$ as well as the bulk modulus $K$.

Using the previously described material modeling, a simulation of the piston-cylinder test set-up is assembled. The piston, the cylinder and the paraffin wax are modelled as deformable axial symmetric bodies using a 4-node axisymmetric thermally coupled quadrilateral, bilinear displacement and temperature element (type CAX4T). The element size of the paraffin wax body is reduced to an edge length of $0.5 \mathrm{~mm}$ to reach converging results. The cylinder has an element edge length of $1 \mathrm{~mm}$ 
and the cylinder of $3 \mathrm{~mm}$. The complete model has an initial temperature of $27^{\circ} \mathrm{C}$. The heating cartridges are modelled as a temperature boundary condition in the cylinder wall and the piston center. The simulation is divided into two sections. First, the contact between all components is established by applying the axial force $F_{\mathrm{a}}$ onto the piston in an implicit step. In the second stage, the temperature of the heating cartridges is applied with the described boundary conditions, utilizing a coupled implicit temperature-displacement calculation. In both sections, the resulting piston height $h_{\mathrm{p}}$ is recorded.

Table 3. Gradient of change of force and change of paraffin height, deviation of the gradient, change of initial absolute piston height at temperature $\theta$.

\begin{tabular}{ccccc}
\hline $\boldsymbol{\theta}_{\mathbf{t}}$ in ${ }^{\circ} \mathbf{C}$ & $\Delta \boldsymbol{F} / \Delta \boldsymbol{h}_{\mathbf{p}}$ in $\mathbf{N} / \mathbf{m m}$ & $\Delta$ & $\Delta \boldsymbol{h}_{0, \boldsymbol{\theta}}$ in $\mathbf{m m}$ & $\boldsymbol{K}$ in $\mathbf{N} / \mathbf{m m}^{\mathbf{2}}$ \\
\hline 50 & 120,744 & 2.519 & 1.835 & 1008.0 \\
55 & 106,434 & 2.504 & 2.785 & 931.1 \\
60 & 123,714 & 1.054 & 3.309 & 1110.0 \\
65 & 119,873 & 1.464 & 3.441 & 1081.0 \\
70 & 115,126 & 1.055 & 3.561 & 1045.0 \\
\hline
\end{tabular}

Figure 5 shows the numerical results in comparison to the experimental data. For all calculated axial forces $F_{\mathrm{a}}$, there is a good correlation between numerical and experimental results for the change in piston height $h_{\mathrm{p}}$. All calculated results are below the experimental data. The deviation is $3 \%$ or less and therefore the model shows sufficient results for the axial force range from $F_{\mathrm{a}}=0.15 \mathrm{kN}-80 \mathrm{kN}$.

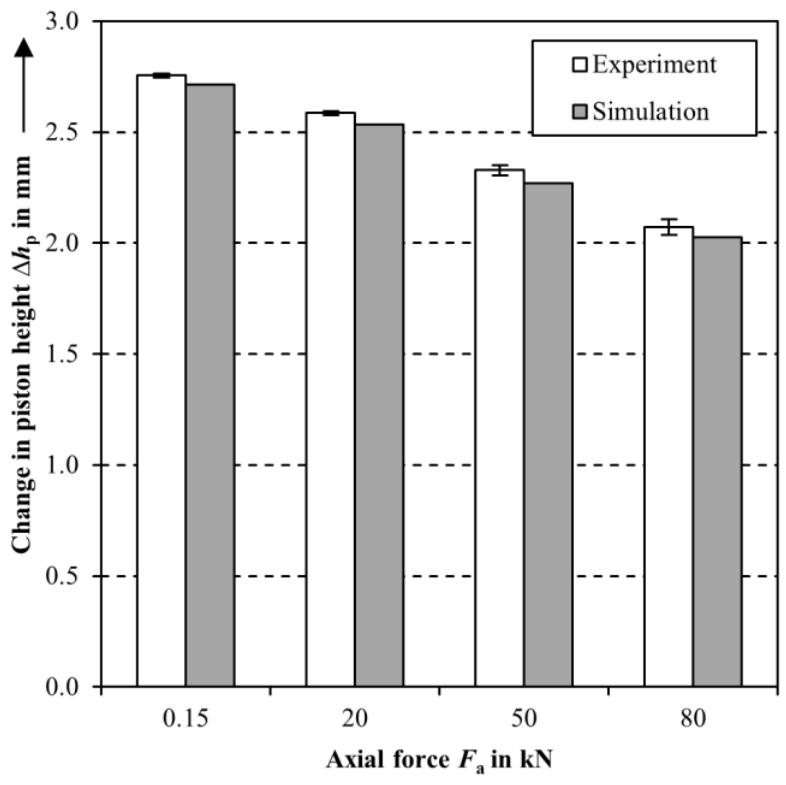

Figure 5. Comparing change in piston height $\Delta h_{\mathrm{p}}$ of experimental and simulated data for different axial forces $F_{\mathrm{a}}$.

\section{Property Prediction and Experimental Validation of a Closed Paraffin Wax Actuator}

In the following, a model of the paraffin wax actuator is set up using the prior described paraffin wax model. The planned experimental setup for characterizing the actuator was modeled in the finite element simulation. In both scenarios, the actuator's vertical elongation is repressed and the resulting axial force $F_{\mathrm{a}}$ during the heating of the actuator is recorded.

Figure 6 shows an axial symmetric view of the paraffin wax actuator from the experiment and the simulation. The housing consists of an outer cup and an inner cup (steel grade DP600) with the geometric parameters from Table 4. 


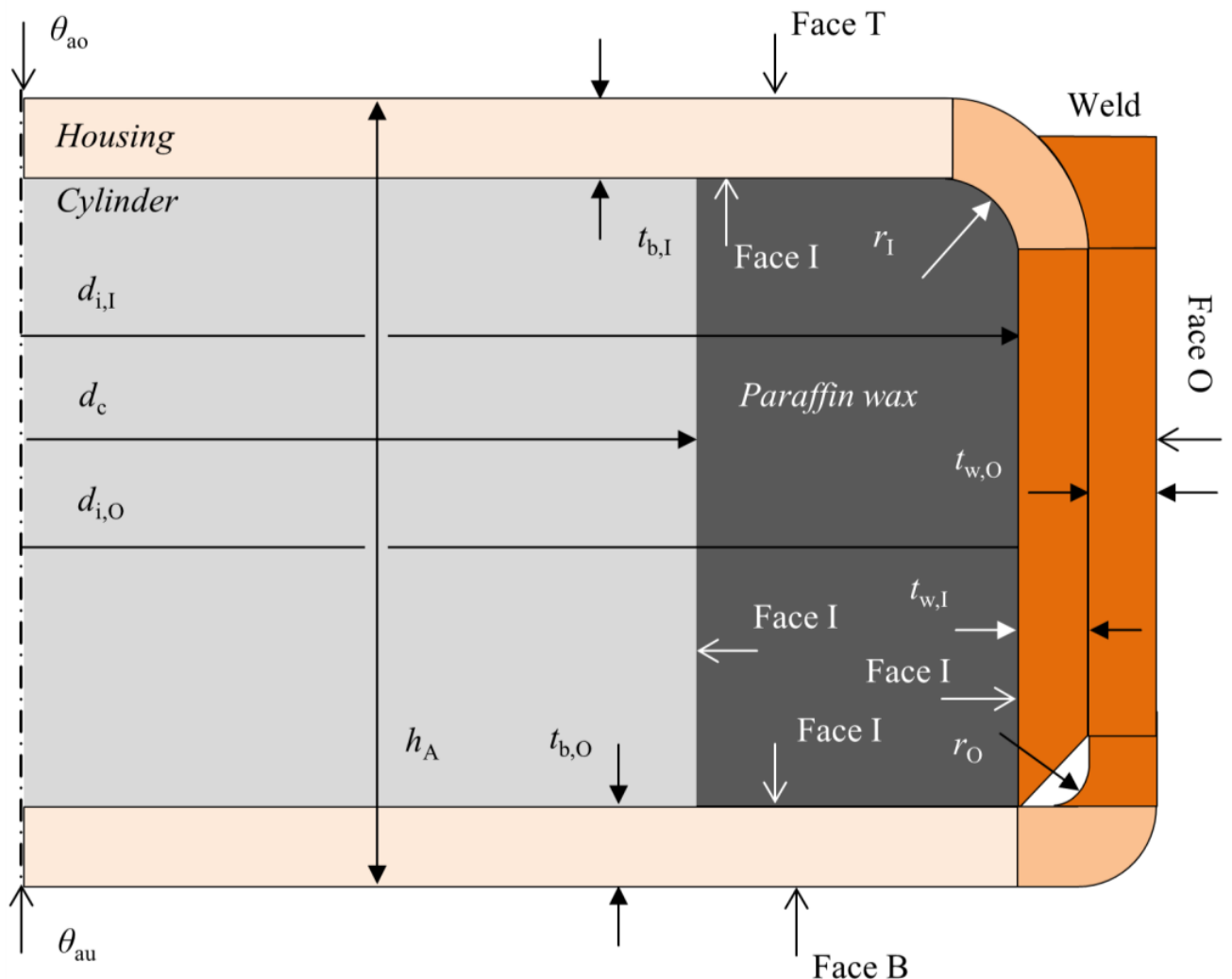

Figure 6. Axial symmetric view of the actuator's fem model.

Table 4. Geometric parameters of the actuator.

\begin{tabular}{ccc}
\hline & Inner Cup (I) & Outer Cup (O) \\
\hline Diameter $d_{\mathrm{i}}$ in mm & 27.00 & 28.75 \\
Thickness bottom $t_{\mathrm{b}}$ in mm & 1.00 & 1.00 \\
Thickness wall $t_{\mathrm{w}}$ in mm & 0.80 & 0.80 \\
Radius $r_{\mathrm{I}}, r_{\mathrm{O}}$ in mm & 1.00 & 0.50 \\
Material [-] & DP600 & DP600 \\
\hline
\end{tabular}

A cylinder $\left(d_{\mathrm{c}}=20.0 \mathrm{~mm}, 22.5 \mathrm{~mm}, 25.0 \mathrm{~mm}\right)$ is positioned in the middle of the actuator surrounded by paraffin wax. The actuator is surrounded by an aluminum ring which generates an even temperature distribution over the perimeter and contains three thermocouples to control the target temperature $\theta_{\mathrm{t}}$. There is a heater band around the aluminum ring. The paraffin wax volume can be adjusted by changing the cylinder diameter $d_{\mathrm{c}}$ in the actuator. The paraffin wax exerts pressure on the inner Face I due to its volume increase. The pressure leads to an axial force $F_{\mathrm{a}}$. At face $\mathrm{T}$ and face $\mathrm{B}$ compression pads (steel grade 1.2379) are positioned to apply the counter pressure and connecting the actuator to the compression test machine (Zwick Roell 100). Thermocouples are placed in the center of the compression pads to record the temperatures $\theta_{\mathrm{ao}}$ and $\theta_{\mathrm{au}}$. In the simulation, the vertical displacement of the compression pads is set to zero by a boundary condition. In the experiment, an optical system references the upper and lower compression pad to a constant distance. Between compression pad and test machine, two insulation plates are positioned to reduce the heat transfer into the test machine. The film coefficient for the outer surfaces is set between $0.01-0.03 \mathrm{~W} /\left(\mathrm{mm}^{2} \mathrm{~K}\right)$ in the simulation to model natural convection.

Figure 7 compares measured and calculated temperatures of the actuator with cylinder diameter $d_{\mathrm{c}}=22.5 \mathrm{~mm}$ from the experiment and the simulation. The target temperature is set to $\theta_{\mathrm{t}}=90^{\circ} \mathrm{C}$. The experimental target temperature $\theta_{\mathrm{t}, \exp }$ shows a steep temperature incline with a decreasing gradient until reaching $90^{\circ} \mathrm{C}$. In the simulation, the target temperature $\theta_{\mathrm{t}, \mathrm{fem}}$ is set as a boundary condition. 
The target temperature $\theta_{\mathrm{t}, \text { fem }}$ reaches its maximum of $90{ }^{\circ} \mathrm{C}$ at the same point as the experimental target temperature $\theta_{\mathrm{t}, \exp }$. In the following, the experimental target temperature $\theta_{\mathrm{t}, \exp }$ oscillates around the value of $90^{\circ} \mathrm{C}$ due to the used control, whereas the simulated target temperature $\theta_{\mathrm{t}, \text { fem }}$ is constant. A complete test cycle lasts $1500 \mathrm{~s}$. Furthermore, Figure 7 shows the top actuator temperature $\theta_{\text {ao }}$ and the bottom actuator temperature $\theta_{\text {ao }}$ for the simulation (fem) and the experiment (exp). The experimental actuator top $\theta_{\text {ao }}$ and bottom $\theta_{\text {au }}$ temperatures are below the simulated actuator temperatures until the test progress of 0.7 . From this point and further, the simulated and experimental actuator temperatures show a similar behavior. The actuator bottom temperature $\theta_{\text {au }}$ shows a difference of about $5{ }^{\circ} \mathrm{C}$ to the

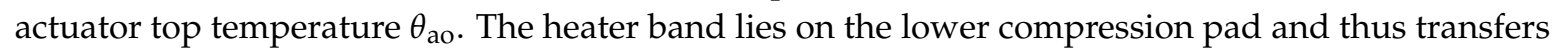
more heat into the lower compression pad and the actuator bottom. The simulated heat distribution correlates with the experimental results.

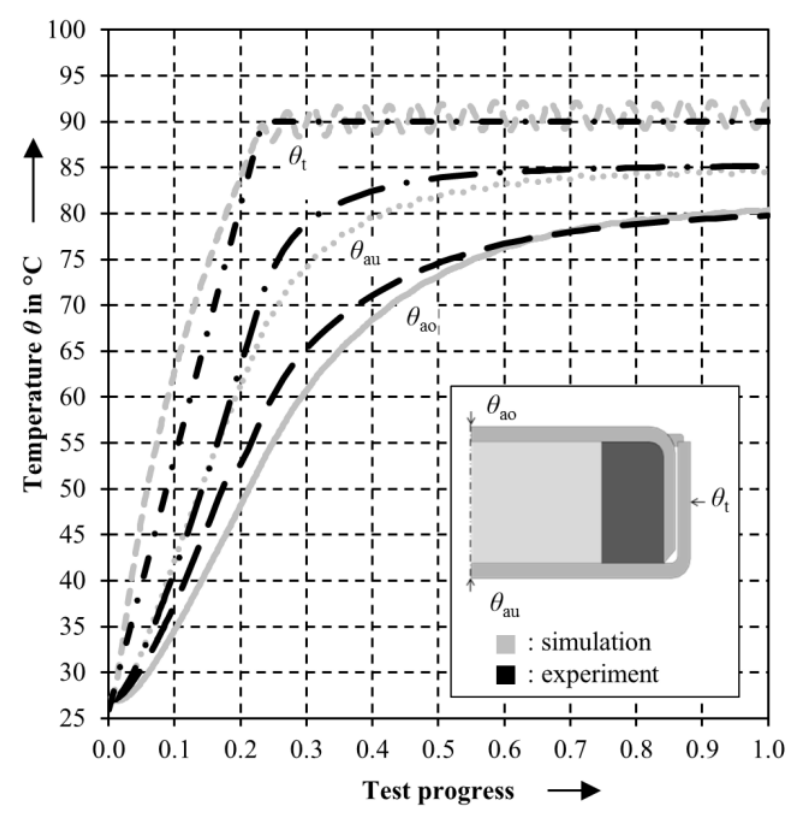

Figure 7. Comparison of experimental and simulated temperatures $\theta$ with $d_{\mathrm{c}}=22.5 \mathrm{~mm}$. Positions: actuator top (ao), actuator bottom (au), and target temperature (t).

The heating of the actuators with different integrated cylinders show a qualitative similar progress of the axial forces $F_{\mathrm{a}}$ over the test progress (Figure 8). The axial force $F_{\mathrm{a}}$ increases from the start of the test until reaching an inflection point, changing to a linear behavior which changes into a decreasing axial force gradient until the maximum plateau is reached. The inflection point is located between 0.2 and 0.3 of the test progress for all cylinder diameters. At this point, the paraffin wax reaches the temperature of $\theta=58{ }^{\circ} \mathrm{C}$. The melting area of the used paraffin wax begins. In the simulation, the melting process is modeled using the latent heat which is required for the phase transition and using a change of the heat conduction (Table 1). On the one side, the heat conduction is increasing from $0.21 \mathrm{~W} / \mathrm{mK}$ to $4.2 \mathrm{~W} / \mathrm{mK}$ and should accelerate the increase in axial force. On the other side, the necessary heat for changing from solid to liquid phase must be induced into the system. Combined, the latent heat effect is visible in the graph's course and the actuator behavior shows an inflection point with a decreasing axial force gradient. The amount of paraffin wax has an effect on the response time of paraffin wax actuators, which can be seen at varying inflection points. The actuator with the cylinder diameter $d_{\mathrm{c}}=25.0 \mathrm{~mm}$ reaches $\theta=58{ }^{\circ} \mathrm{C}$ at $0.22\left(d_{\mathrm{c}}=22.5 \mathrm{~mm}\right.$ at 0.25 and $d_{\mathrm{c}}=20.0 \mathrm{~mm}$ at 0.26$)$. 


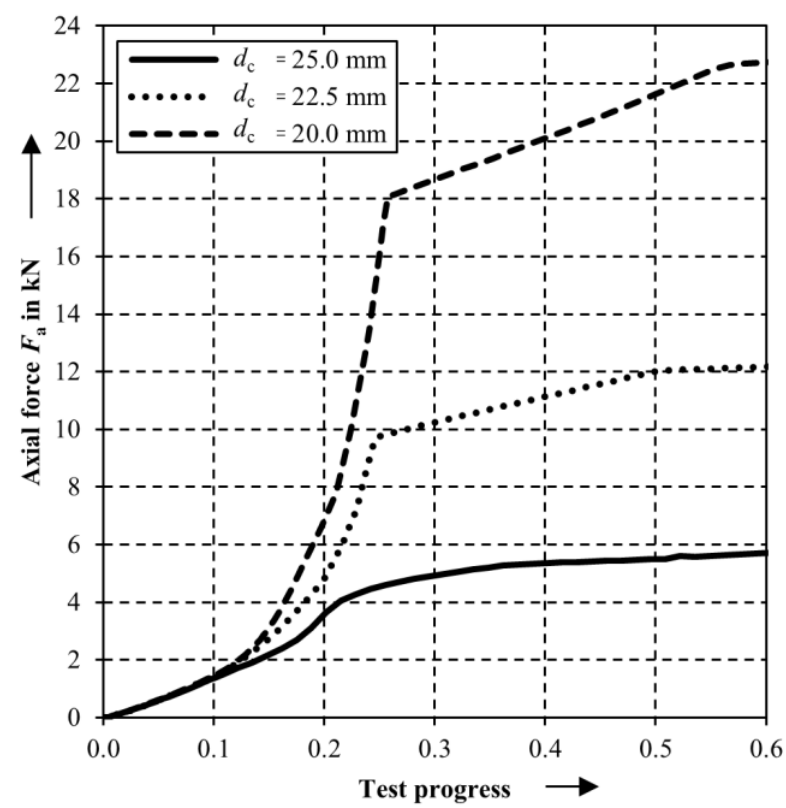

Figure 8. Simulated axial forces $F_{\mathrm{a}}$ for different cylinder diameters $d_{\mathrm{c}}$ showing different reaction times.

The experiment shows a corresponding behavior to the simulated actuators (Figure 9). As in the simulation, a complete test cycle lasts $1500 \mathrm{~s}$. Compared to the simulation, the actuator with the cylinder $d_{\mathrm{c}}=22.5 \mathrm{~mm}$ shows a delayed increase in axial force in the experiment until reaching test progress 0.11 . After the steep increase, the axial force shows an inflection point as predicted, whereas the inflection point is not as explicit as in the simulation. After the inflection point, the axial force trends to its maximum.

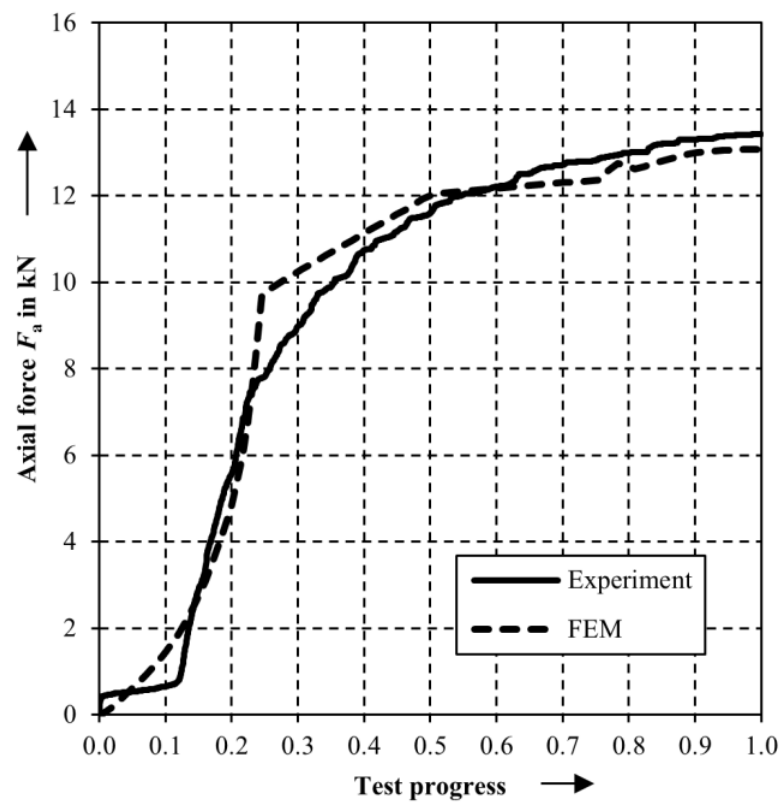

Figure 9. Axial force $F_{\mathrm{a}}$ over test progress for the actuator with the cylinder diameter $d_{\mathrm{c}}=22.5 \mathrm{~mm}$.

Figure 10 shows the maximum axial force $F_{\mathrm{a} \text {,max }}$ taken from the experiment and the simulation for actuators with different integrated cylinders of the size $d_{c}=20.0 \mathrm{~mm}, 22.5 \mathrm{~mm}, 25.0 \mathrm{~mm}$, and for actuators without cylinder. With increasing cylinder diameter $d_{c}$ and a resulting declining paraffin volume, the maximal axial force $F_{\mathrm{a}, \max }$ decreases. The actuator with the cylinder diameter $d_{\mathrm{c}}=20.0 \mathrm{~mm}$ acquires an average maximum force $F_{\mathrm{a}, \max }=22.9 \mathrm{kN}$. The actuator with the cylinder 
diameter $d_{\mathrm{c}}=22.5 \mathrm{~mm}$ reaches $F_{\mathrm{a}, \max }=13.8 \mathrm{kN}$ and $d_{\mathrm{c}}=25.0 \mathrm{~mm}$ results in $F_{\mathrm{a}, \max }=5.6 \mathrm{kN}$ at the target temperature $\theta_{\mathrm{t}}=90^{\circ} \mathrm{C}$. The actuator without cylinder reaches an average maximum force $F_{\mathrm{a}, \max }=41.4 \mathrm{kN}$ at the target temperature $\theta_{\mathrm{t}}=70^{\circ} \mathrm{C}$. The simulated maximum forces correspond with the experimental data, in which the standard deviation for the cylinder diameters $d_{\mathrm{c}}=22.5 \mathrm{~mm}$ and $d_{\mathrm{c}}=20.0 \mathrm{~mm}$ seem to be high. The deviation in maximum force for the actuator without cylinder is $2.7 \mathrm{kN}$ and is therefore about $6 \%$.

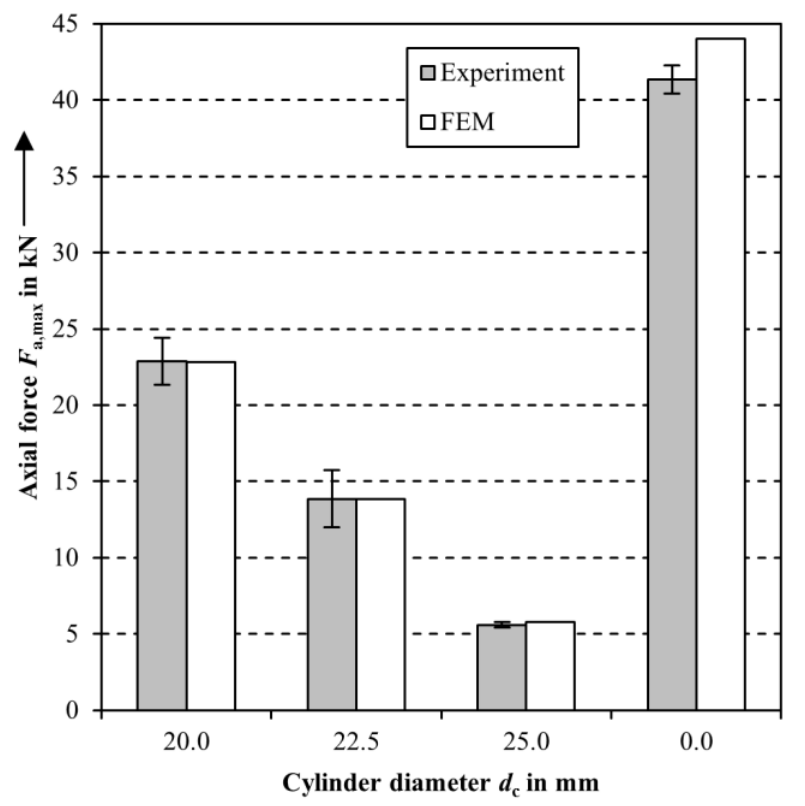

Figure 10. Maximum axial force $F_{\mathrm{a}, \max }$ and its standard deviation for different cylinder diameters $d_{\mathrm{c}}$ for the temperature $\theta_{\mathrm{t}}=90^{\circ} \mathrm{C}$ and $\theta_{\mathrm{t}}=70{ }^{\circ} \mathrm{C}$ for $d_{\mathrm{c}}=0.0 \mathrm{~mm}$.

The root cause for the deviations may be the variation in the manufacturing process. Especially the paraffin wax filling and the laser welding process must be investigated more detail. In summary, the calculated temperature distribution and actuator forces by simulation correspond well with the experimental data. The issued paraffin wax model can predict the behavior of a closed paraffin wax actuator.

For the actuator without cylinder, Figure 11 shows the axial forces over the displacements for the temperatures $\theta_{\mathrm{t}}=50{ }^{\circ} \mathrm{C}, 60{ }^{\circ} \mathrm{C}$, and $70{ }^{\circ} \mathrm{C}$. The data is recorded after heating the actuator for $1200 \mathrm{~s}$. After the heating, the compression test machine initiates a displacement of $w_{\mathrm{a}}=0.1 \mathrm{~mm}$ of the compression pad with $0.01 \mathrm{~mm} / \mathrm{s}$ followed by a change in direction and returning to the initial displacement $w_{\mathrm{a}}=0.0 \mathrm{~mm}$. For the tested temperatures, the axial force is decreasing with increasing displacement. The correlation between displacement and axial force seems to be linear. Furthermore, the axial force increases after returning to the displacement $w_{\mathrm{a}}=0.0 \mathrm{~mm}$. The actuator shows hysteresis behaviour. The descents in axial force for the displacements $w_{\mathrm{a}}=0.0 \mathrm{~mm}$ compared to $w_{\mathrm{a}}=0.1 \mathrm{~mm}$ are $7.1 \mathrm{kN}$ for $\theta_{\mathrm{t}}=50{ }^{\circ} \mathrm{C}, 9.5 \mathrm{kN}$ for $\theta_{\mathrm{t}}=60^{\circ} \mathrm{C}$, and $11.1 \mathrm{kN}$ for $\theta_{\mathrm{t}}=70^{\circ} \mathrm{C}$.

The maximum axial force declines to $32.4 \%$ for $\theta_{\mathrm{t}}=50{ }^{\circ} \mathrm{C}, 57.2 \%$ for $\theta_{\mathrm{t}}=60{ }^{\circ} \mathrm{C}$, and $72.6 \%$ for $\theta_{\mathrm{t}}=70{ }^{\circ} \mathrm{C}$ in relation to the maximum axial force. The decrease in axial force with increasing displacement is increasing with higher temperatures, but in relation to the initial maximum force it is decreasing. The shown actuator design seems appropriate for acting in resilient production processes and other applications. 


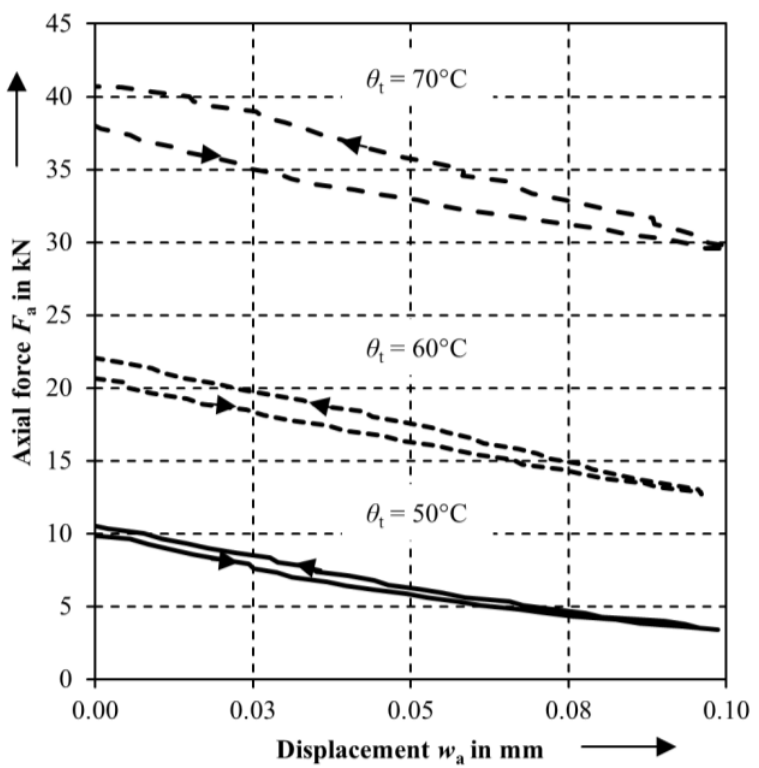

Figure 11. Axial force displacement diagram for the actuator without cylinder.

\section{Conclusions}

This paper presents a closed paraffin wax actuator design and a guideline for modeling paraffin wax actuators. For varying the paraffin wax volume and achieving a known stiffness in axial direction, a cylinder is positioned in the center of the actuator. Using the piston-cylinder test stand, the necessary temperature-dependent volume expansion and Young's modulus data for the used paraffin wax are recorded. The modeling of the paraffin wax as a deformable body shows promising results in the simulation of the piston-cylinder test stand. As a result, the paraffin wax model is used to build a simulation of the shown paraffin wax actuator design. The simulations of the actuators with different integrated cylinders show a good correlation in the prediction of the time-dependent temperature distribution and the actuator forces. Finally, an axial force relating to the displacement of the actuator without cylinder is shown. The actuator design achieves significantly higher forces than other actuator designs.

Author Contributions: Conceptualization, A.M.; methodology, A.M.; software, A.M.; validation, A.M. and C.M.B.; formal analysis, A.M. and C.M.B.; investigation, A.M. and C.M.B.; resources, A.M.; data curation, A.M.; writing - original draft preparation, A.M. and P.G.; writing—review and editing, A.M. and P.G.; visualization, A.M.; supervision, A.M. and P.G.; project administration, A.M.; funding acquisition, A.M. and P.G.

Funding: The authors want to express their gratitude to the German Research Foundation DFG (Deutsche Forschungsgemeinschaft) for the support of the grant "Design methods for Novel, Energy-Efficient, Closed Phase Change Actuators with High Action of Force" (GR 1818/65-1).

Acknowledgments: We acknowledge support by the German Research Foundation and the Open Access Publishing Fund of Technische Universität Darmstadt.

Conflicts of Interest: The authors declare no conflict of interest.

\section{References}

1. Allwood, J.M.; Duncan, S.R.; Cao, J.; Groche, P.; Hirt, G.; Kinsey, B.; Kuboki, T.; Liewald, M.; Sterzing, A.; Tekkaya, A.E. Closed-loop control of product properties in metal forming. CIRP Ann. 2016, 65, 573-596. [CrossRef]

2. Al-Faqheri, W.; Ibrahim, F.; Thio, T.H.G.; Moebius, J.; Joseph, K.; Arof, H.; Madou, M. Vacuum/Compression Valving (VCV) using parrafin-wax on a centrifugal microfluidic CD platform. PLoS ONE 2013, 8, e58523. [CrossRef] [PubMed] 
3. Baek, S.-K.; Yoon, Y.-K.; Jeon, H.-S.; Seo, S.; Park, J.-H. A wireless sequentially actuated microvalve system. J. Micromech. Microeng. 2013, 23, 45006. [CrossRef]

4. Bodén, R.; Lehto, M.; Schweitz, J.-Å. A Paraffin Driven Linear Microactuator for High Force and Large Displacement Applications. In Actuator 2006, Proceedings of the 10th International Conference on New Actuators $\mathcal{E}$ 4th International Exhibition on Smart Actuators and Drive Systems, Bremen, Germany, 14-16 June 2006; Borgmann, H., Ed.; HVG Hanseatische Veranstaltungs-GmbH, Division Messe Bremen: Bremen, Germany, 2006; pp. 720-723.

5. Kabei, N.; Kosuda, M.; Kagamibuchi, H.; Tashiro, R.; Mizuno, H.; Ueda, Y.; Tsuchiya, K. A thermalexpansion-type microactuator with paraffin as the expansive material: Basic performance of a prototype linear actuator. JSME Int. J. Ser. C 1997, 40, 736-742. [CrossRef]

6. Klintberg, L.; Karlsson, M.; Stenmark, L.; Schweitz, J.-Å.; Thornell, G. A large stroke, high force paraffin phase transition actuator. Sens. Actuators A Phys. 2002, 96, 189-195. [CrossRef]

7. Jonsson, J.; Ogden, S.; Johansson, L.; Hjort, K.; Thornell, G. Acoustically enriching, large-depth aquatic sampler. Lab Chip 2012, 12, 1619-1628. [CrossRef] [PubMed]

8. Carlen, E.T.; Mastrangelo, C.H. Paraffin actuated surface micromachined valves. In Proceedings of the Thirteenth Annual International Conference on Micro Electro Mechanical Systems (MEMS), Miyazaki, Japan, 23-27 January 2000; pp. 381-385.

9. Ogden, S.; Jonsson, J.; Thornell, G.; Hjort, K. A latchable high-pressure thermohydraulic valve actuator. Sens. Actuators A Phys. 2012, 188, 292-297. [CrossRef]

10. Boden, R.; Lehto, M.; Simu, U.; Thornell, G.; Hjort, K.; Schweitz, J.-A. A polymeric paraffin micropump with active valves for high-pressure microfluidics. In Proceedings of the 13th International Conference on Solid-State Sensors, Actuators and Microsystems (TRANSDUCERS '05), Seoul, Korea, 5-9 June 2005; p. 201.

11. Svensson, S.; Sharma, G.; Ogden, S.; Hjort, K.; Klintberg, L. High-pressure peristaltic membrane micropump with temperature control. J. Microelectromech. Syst. 2010, 19, 1462-1469. [CrossRef]

12. Walsh, D.; Zoller, P. Standard Pressure Volume Temperature Data for Polymers; CRC Press: Boca Raton, FL, USA, 1995.

13. Spengler, G.; Wilderotter, M. Zur Rheometrie von Wachsen und Paraffinen 11: Ein Beitrag zum Viskositats-und Fließverhalten Wachsartiger Korper; Technische Hochschule München: München, Germany, 1964. (In German)

14. Ogden, S.; Klintberg, L.; Thornell, G.; Hjort, K.; Bodén, R. Review on miniaturized paraffin phase change actuators, valves, and pumps. Microfluid. Nanofluid. 2013, 17, 53-71. [CrossRef]

15. Henze, R.H.; Humphrey, J.A.C. Enhanced heat conduction in phase-change thermal energy storage devices. Int. J. Heat Mass Transf. 1981, 24, 459-474. [CrossRef]

16. Costa, M.; Buddhi, D.; Oliva, A. Numerical simulation of a latent heat thermal energy storage system with enhanced heat conduction. Energy Convers. Manag. 1998, 39, 319-330. [CrossRef]

17. Brousseau, P.; Lacroix, M. Numerical simulation of a multi-layer latent heat thermal energy storage system. Int. J. Energy Res. 1998, 22, 1-15. [CrossRef]

18. Kratz, H.; Eriksson, A.; Karlsson, M.; Kohler, J.; Thornell, G. Analysis of Thermal Transients in an Asymmetric Silicon-Based Heat Dissipation Stage. IEEE Trans. Comp. Packag. Technol. 2007, 30, 444-456. [CrossRef]

19. Lee, J.S.; Lucyszyn, S. Thermal analysis for bulk-micromachined electrothermal hydraulic microactuators using a phase change material. Sens. Actuators A Phys. 2007, 135, 731-739. [CrossRef]

20. Lee, J.S.; Lucyszyn, S. Design and pressure analysis for bulk-micromachined electrothermal hydraulic microactuators using a PCM. Sens. Actuators A Phys. 2007, 133, 294-300. [CrossRef]

21. Gowreesunker, B.L.; Tassou, S.A.; Kolokotroni, M. Improved simulation of phase change processes in applications where conduction is the dominant heat transfer mode. Energy Build. 2012, 47, 353-359. [CrossRef]

22. Kong, Q.; Ma, J.; Che, C. Theoretical and experimental study of volumetric change rate during phase change process. Int. J. Energy Res. 2009, 33, 513-525. [CrossRef]

23. Malik, A.; Ogden, S.; Amberg, G.; Hjort, K. Modeling and analysis of a phase change material thermohydraulic membrane microactuator. J. Microelectromech. Syst. 2013, 22, 186-194. [CrossRef]

24. Bodén, R.; Hjort, K.; Schweitz, J.-Å.; Simu, U. A metallic micropump for high-pressure microfluidics. J. Micromech. Microeng. 2008, 18, 115009. [CrossRef]

25. Ukrainczyk, N.; Kurajica, S.; Šipušić, J. Thermophysical comparison of five commercial paraffin waxes as latent heat storage materials. Chem. Biochem. Eng. Q. 2010, 24, 129-137. 
26. Wolf, F.P. Präzisionsmessungen des Elastizitätsmoduls von Polymeren mit Longitudinalschwingungen. Colloid Polym. Sci. 1979, 257, 1133-1158. (In German) [CrossRef]

27. Craig, R.G.; Eick, J.D.; Peyton, F.A. Strength Properties of Waxes at Various Temperatures and Their Practical Application; University of Michigan: Ann Arbor, MI, USA, 1967.

28. Schaerer, A.A.; Busso, C.J.; Smith, A.E.; Skinner, L.B. Properties of pure normal alkanes in the C17 to C36 range. J. Am. Chem. Soc. 1955, 77, 2017-2019. [CrossRef] 